\title{
EL LIBRO DE FOB: QUEVEDO, MODERNIZADOR DEL ESPAÑOL EN UN TRATADO DOCTRINAL
}

A los sufridos universitarios españoles.

El Tratado de la Constancia, y Paciencia del Santo Job en sus pérdidas, enfermedades y persecuciones, escrito en la prisión del Convento de San Marcos de León, en 1641, y terminado de corregir y completar en 1642, pertenece, por tanto, a la última etapa de la vida de Quevedo. Fue publicado por primera vez en 1713 , en la colección llamada del león, impresa en Madrid, en la imprenta de Manuel Román, en el tomo de Vida y Obras posthumas de Don Francisco de Quevedo. Parte tercera, edición reproducida en 1724 por Juan de Ariztia, en Madrid, que manejamos.

Tanto la edición de 1713 como la de 1724 la imprimen como tercer tratado del libro Providencia de Dios, padecida de los que la niegan, y gozada de los que la confiessan. Doctrina estudiada en los gvsanos, $y$ persecuciones de Job. Sin embargo, la crítica está de acuerdo en su carácter de libro independiente (del Piero: 1958 y 1959, reelaborados en 1969, obra básica sobre el Job). De hecho, la edición de la Providencia de 1700 [citada por A. Fernández-Guerra en el catálogo de ediciones que precede a la suya de la BAAEE (1852)] impresa en Zaragoza por Pasqual Bueno, no la recogía. Lo sucedido fue que, a partir de 1713, se dividió el texto editado en 1700 en dos tratados ( 1 la inmortalidad del alma» y «la incomprehensible disposición de Dios en las felicidades, y sucesos prosperos, que los del mundo llaman bienes de fortunax), añadiéndose a ellos, como supuesto tratado tercero, la Constancia $y$ Paciencia del Santo Job. 
El Libro de Job tiene varios atractivos: se inscribe en una tradición española que dedica al paciente patriarca obras de indudable calidad, entre las que cabe destacar la de Fray Luis de León (del Piero: 1969, p. 19, n. 5); se relaciona con un, al parecer, inexistente Themanites redivivus in Job, con cuya autoría se adornó Quevedo en el proemio «al doctísimo y reverendísimo Padre Fray Cristóbal de Torres", en La Cuna y la Sepultura (del Piero: 1969, 22-23), recogido por Pérez de Montalbán en el Para Todos (p. 519 en la edición de Alcalá, 1661, citada por del Piero, ibid. 23, n. 3), y criticado por Jáuregui en El retraído. Del Piero $(1969,26)$, apoyado en que Jáuregui pone en duda su existencia calificándolo de «artificio», y hablando de que «salen a luz admirables obras y volúmenes, sin demasiado sudor de los autores», en que Tarsia no lo cita, y en que el Job castellano que conservamos refleja con toda claridad sus fuentes, que no parecen depender de una obra latina anterior de su autor, rechaza que haya existido nunca este Themanites redivivus, cuyo nombre parece ya uno de los juegos conceptuales a que tan aficionado era el señor de la Torre de Juan Abad; nos proporciona - volviendo a sus atractivos- un testimonio directo y vivido de su prisión y cautiverio, y, por último, desde el punto de vista linguístico es un trabajo completo, tanto en lo que muestra la maestría de traductor del poeta, como en su dominio de los recursos linguiísticos que la evolución de la lengua y sus posibilidades de modernización le ofrecen, tras la reforma humanista o renacentista.

La censura del reverendísimo padre maestro Juan Manuel de Arguedas de la Compañía de Jesús (Fernández Guera, CXXIV b, reproducida también en la edición de 1724), al frente de la edición de 1713, expone resumidamente el contenido del libro, a la vez que adelanta un juicio de su intención, recogiendo rápidamente una noticia de sus vicisitudes:

El Tratado Pósthumo de la Immortalidad del Alma, que dedico en su vltima prision de Leon à su confessor el P. Mauricio de Atondo [la dedicatoria, ed. 1724, pág. 103, y Fernández Guerra, CXXIV-V, traen Attodo] de la Compañia de Jesvs, Lector de Theologia en aquel Colegio. Los Commentarios de Job, la Providencia divina (que tanto han deseado la luz pública) son a juizio de los Doctos vn seguro Baluarte, o vn Castillo Roquero contra todos los Hereges del Norte, que poniendo nombres distintos à sus errores, ni son lo que defienden, ni saben lo que se dizen, pues negando el merito y el premio, quitan al Alma su immortalidad, y à Dios su Providencia y Divinos atributos; y quien à Dios quita algo de su infinito sèr, se lo quita todo: y esto es ser Atheísta, aunque no les contenta esta voz. 
La «Advertencia Previa, y Recomendación destas Obras Posthumas de Don Francisco de Quevedo" proporciona otros detalles complementarios, que nos permitimos recoger (ed. 1724, p. 99):

Entre los papeles originales destas Obras Posthumas de Don Francisco de Quevedo y Villegas, todas escritas por su mano, se han encontrado quatro cartas de aquel incomparable Varon el Illustrissimo, y Reverendissimo señor don Bartholomè Santos de Risoba, Obispo que era de Leon, quando Don Francisco de Quevedo las escrivia; de cuyo Prelado en el tom. I. de su Teatro Eclesiastico Hispano, el Maestro Gil Gonçalez Davila haze vn elogio, y $\langle y\rangle$ recomendacion tan honorifica, como podrà ver el curioso. Este Insigne Varon hallabase gavernando (sic) aquella Diocesi, como Pastor vigilantissimo, al tiempo que D. Francisco de Quevedo estaba preso en el Convento de San Marcos de Leon, lleno de trabajos, enfermedades, y horrores; y como los hombres grandes tienen cierta sympatia, y parentesco en las almas, hallo Don Francisco, no solo consuelo en sus grandes trabaios con la comunicacion de este grande, y piadosissimo Principe; s[i]no que es tradicion constante, que le exorto a escrivir estos Tratados, para que el desengaño que logrò en sus ultimos años llenos de calamidad, y miseria, Don Francisco los comunicasse al bien publico, y lograsse este fruto dichoso la Republica Christiana para bien de las almas. Remitiale libros de su gran Libreria; y remitiale Don Francisco los cartapacios que iba escriviendo para corregirlos; y en lugar de correccion se los bolvia, exortandole à proseguir, venerando su erudicion, y estudio, como vn humilde discipulo à vn Maestro Sapientissimo...

Las cartas del Obispo de León, recogidas luego en el libro, interesantes por las repetidas referencias a las fuentes bibliográficas (del Piero: 1958, 59, 69), y otras vicisitudes de la composición, nos permiten comprobar que el primer cuaderno fue devuelto por éste el lunes 25 de agosto de 1642, el segundo el sábado 30 de agosto de 1642 , y el tercero y último el miércoles 25 de octubre de 1642. Puesto que parece observarse en el texto que Quevedo siguió las indicaciones del obispo en lo concerniente a la necesidad de dar la traducción castellana de las citas latinas, cuando no lo había hecho, podemos fechar perfectamente el libro: una primera redacción de 1641, y una corrección y ampliación de 1642. No hay que olvidar, sin embargo, que estos datos parecen abarcar conjuntamente la Providencia y el Job, editados, desde 1713, como si fueran el mismo libro, según dijimos antes.

El mismo libro proporciona datos autobiográficos, acerca de la prisión de Quevedo, y la fecha de composición (1641), que, aunque conocidos (del Piero: 1969), no nos resistimos a citar (ed. 1724, 251 a- 252 a):

Quiero hablar de mi mismo: debert a mi pluma, lo que quien leyere, deberà à mi exemplo. [¿] Supiera yo pedir à Dios, o supiera alguna elo- 
quencia persuadirme à que le pidiera por merced, estando huesped de vn grande Señor, no en comparacion de otros chicos, sino de otros grandes, y grandes en letras, y virtudes en las casas del Duque de Alva, Palacio à que por ver su grandeza se peregrina: de sesenta y vn años de edad crecidos de prisiones de doze años, de nueve de navegacion y caminos, yà huesped molesto al cuerpo con once heridas, y las dos abiertas, que me prendiessen dos Alcaldes de Corte, con mas de veinte Ministros, y sin dexarme cosa alguna, y tomandome las llaves de todo, sin vna camisa, ni capa, ni criado, en ayunas à las diez y media de la noche, el dia siete de Diziembre, y en vn coche con vno de los Alcaldes, y dos Alguaciles de Corte, y quatro Guardas me truxessen con apariencia mas de ajusticiado, que de preso en el rigor del hibierno, sin saber à què, ni por què, ni adonde, caminando cinquenta y cinco leguas al Convento Real de San Marcos en Leon de la Orden de Santiago, donde llegue desnudo, y sin vn quarto, y donde estuve seis meses solo en vn aposento, y cerrado por defuera con llave, y adonde sin salir del Convento he estado dos años, que voy prosiguiendo desde siete de Diziembre de treinta y nueve, hasta oy veinte de Octubre de quarenta y vno, con que son catorce los que cuento de carceles rigurosas, sin hazienda por los gastos tan grandes, como nunca se hizieron en prision de Cavallero particular, sin correspondencia humana, muertos en este tiempo los criados que me servian. Molestado con nuevas de que me avian cortado la cabeza, disfamado de las causas que daban à mi trabajo los noveleros y del credito que las daban mis enemigos?

Nuestra dedicación al Libro de Job arranca, por tanto, de varias consideraciones, y se desarrolla en dos líneas, la de la composición literaria y la de la lengua. En lo que concierne a la primera, tras lo anteriormente dicho, queda claro que estamos ante una obra de 1641-42, de plena madurez, intención apologética y doctrinal, ortodoxa; mientras que, en lo que concierne a lo segundo, linguísticamente, además de la misma madurez, tenemos que tener en cuenta $-\mathrm{y}$ en ello insiste, también, el obispo leonés, como rasgo de los escritos de estas circunstancias - la reiterada presencia de textos y elementos latinos, términos religiosos y filosóficos, cultismos, es decir, un campo que puede exigir del escritor una preocupación linguística minuciosa y seria, que se refleja en su acción sobre el instrumento linguístico que maneja.

A partir de estas consideraciones generales, nuestro interés se concretará en los medios lingüísticos que utiliza Quevedo para expresar las opiniones de su libro, en cómo actúa sobre el instrumento para amoldarlo a sus necesidades. Con ello nos situamos deliberadamente en un concepto de Historia de la Lengua puramente activo (lo que no significa siempre clara consciencia del escritor).

En este concepto hemos de referirnos a términos como los de reforma y modernización de la lengua (Marcos: 1979). La reforma de la 
lengua es una actuación sobre la misma para adecuarla a las necesidades de su tiempo, a las necesidades presentes; la modernización es la concreción o el resultado de esa actuación, de esa reforma. Hemos defendido (en el libro citado) que el español ha sufrido cuatro reformas a lo largo de su historia, y cómo éstas pueden considerarse parte central o principal de cada una de sus etapas históricas. La primera es la alfonsí, de la segunda mitad del XIII, la segunda la humanística de fines del XV principio del XVI, la tercera la académica de 1726-41, y la cuarta la actual.

La época de Quevedo es, por tanto, intermedia entre las reformas que, por simplificar, llamaremos humanística y académica, respectivamente. En consecuencia, debemos esperar que Quevedo no sea un reformador de la lengua, sino un modernizador, lo cual requiere alguna nota aclaratoria: un reformador sería, de acuerdo con los conceptos de reforma y modernización expuestos, una persona que se enfrenta activamente con la realidad de una lengua concreta, sobre la cual actúa. El reformador no sólo es consciente, sino también intencionado; suele ser, por ello, un gramático, filólogo, o, en los términos más amplios, un teórico del lenguaje con posibilidades de aplicación práctica, es decir, técnicas o, si se quiere, con una extensión de significado en boga: un político del lenguaje; el reformador hace política linguiística, plantea la situación y da sus pautas para resolver los problemas enunciados. En este sentido decimos que el reformador es un legislador. El modernizador, en cambio, es «ejecutivo", es el ejecutor de la reforma. La diferencia es importante, ya que, naturalmente, los reformadores tratarán de ser modernizadores, mientras que estos últimos no son, necesariamente, lo primero. Los problemas de reforma del español se plantean, como tales, entre fines del XV y mediados del xvI; la modernización correspondiente se prolonga al siglo siguiente, alcanza su culminación entre 1605 y 1650 - fechas simbólicas-, y se alarga, en decadencia, hasta 1714 o 1726, cuando se inicia la reforma siguiente (Sarmiento: 1789).

Así considerados, ni Cervantes, ni Lope, ni Quevedo, ni tampoco Góngora, son reformadores (sí lo serían Nebrija, Valdés, y, probablemente ambas cosas, Herrera y Fray Luis). Los primeros son escritores que hacen la reforma, no teóricos que la plantean. Se enfrentan con la lengua por necesidad del instrumento, concreta, no por preocupación inmanente 0 , al menos, general. Se puede objetar que la necesidad es la que mueve la reforma, y que Alfonso X, ejemplo palmario, es ejecutor tanto o más que impulsor o legislador. Sin embargo, el caso alfonsí es extremo y no se ha repetido - y tal vez no sea deseable que el poder LXV, $1 .^{\circ}-2.0^{\circ}-3$ 
y el conocimiento, el saber, vuelvan a estar del mismo modo concentrados en una mano, por el riesgo totalitario que implica. Después, ni los humanistas, ni la Academia del xvIII, ni las Academias actuales, ni instituto o institución alguno han tenido parecidas posibilidades de llevar a la práctica lo que se consideraría preferible, o necesario: testigos, los dislates idiomáticos de todos los tiempos.

Volvamos a nuestro autor. En un trabajo de finalidad netamente distinta de la nuestra, y sin posible relación teórica, F. Lázaro (1974) ha captado lo que es fundamental de la concepción modernizadora de Quevedo, en cuatro aspectos:

Quevedo utiliza el idioma tal como lo halla.

Evita los elementos modernizadores de tipo exclusivamente léxico, de vocabulario: arcaísmos, vulgarismos, cultismos, neologismos.

Reserva la capacidad de creación para el humor y la sátira. «Crea relaciones y las abandona recién creadas» (p. 35, n. 35).

El resumen de estos conceptos se encierra en este párrafo (32-33):

Quevedo, pues, frente a Góngora, se encierra deliberadamente en el español de su tiempo y se reduce las posibilidades de expresión a los elementos que el caudal idiomático vigente le suministra. No precisa más; y aun a veces se ve arrollado por ese caudal, a fuerza de remover sus más ocultas potencias.

«Deliberadamente», «español de su tiempo» y «caudal que puede arrollar» son conceptos básicos en la exposición de Lázaro Carreter. Sólo cabe una puntualización, que es matiz y no discrepancia, en lo del humor y la sátira. $Y$ hablamos de matiz porque, en efecto, aquí lo que hace es ampliar el registro, extender las posibilidades, crear; pero no porque en el resto de su obra no aparezcan estos procedimientos, lo que ocurre es que aquí ya no son llamativos, detonantes, sino que se van acumulando mansamente. Ese caudal idiomático, arrollador en las obras humorísticas y satíricas, donde se despeña torrencialmente, se remansa y curva en la obra doctrinal o seria; pero, paradójicamente, es en ésta donde deposita el légamo fértil que, como iremos viendo, constituye su obra de modernización. Esta va a ser, en síntesis, la finalidad de estas páginas, recoger los procedimientos de modernización de la lengua que han llamado la atención en los escritos que más se prestan al análisis individual, comprobar cómo esos procedimientos se ajustan a moldes propios del idioma, y ampliar luego este campo mostrando cómo Quevedo hace propio lo que estaba ahí, en la lengua de su época, a disposición 
de todos, y cómo, al hacerlo, da un sentido particular a su magistral manejo de los procedimientos y recursos que habremos analizado, clasificado y descrito.

Manuel Durán (1954) y, poco después, Emilio Alarcos García (1955), con mayor detenimiento, han estudiado algunos de los mecanismos modernizadores, buscando, fundamentalmente, el aspecto estilístico individual, creador, no el de aportación - gigantesca- a la limpieza, fijación y esplendor de la lengua. Por eso es normal que E. Alarcos, en sus conclusiones (p. 37), recoja este párrafo del prólogo de la edición de 1780 del Diccionario académico (págs. IV-V); esta edición, recordemos, es la que suprime las citas de autoridades que dan su nombre habitual al primer diccionario de la corporación. El texto diferencia con claridad los dos aspectos que nos interesan, la invención de la voz (de lo cual se habla) y la disposición de la estructura linguiística para crearla (que es lo que no se explicita):

Se omiten todas las voces inventadas sin necesidad por algún autor, ya sea por jocosidad ó ya por otro qualquier motivo, si después no han llegado á tener uso alguno: como adonicida que usó Lope de Vega por el que mató a Adonis: piogicida que dijo Calderón por el que mata piojos: adanismo que usó Quevedo por el conjunto de gente desnuda, y otras muchas que se forman arbitrariamente en la conversación familiar: cuyas voces, de que hay algunas puestas en el Diccionario, no se deben considerar como parte de la lengua castellana, porque nunca han llegado á tener posesión en ella.

Los investigadores se han dejado seducir por el mismo espejuelo que los académicos: han caído en las redes de los elementos léxicos concretos, de la anécdota léxica, y no han visto los hilos gramaticales. Cuando Quevedo inventa la voz adanismo, lo importante para la lengua no es el ingenio que equipara Adán a 'desnudez', sino la posibilidad de unir el sufijo -ismo a un nombre propio para formar un abstracto de cualidad.

La simple relectura del artículo de Alarcos García, desde esta ladera, nos proporciona una visión distinta: ahora no vamos al rasgo único que configura a su autor como un ingenio, vamos al procedimiento que permite a un usuario linguístico del XviI modernizar la lengua. Por razones metodológicas nos limitaremos al recinto de la palabra, sin entrar en las locuciones, tema que corresponde también a los conceptos de reforma y modernización; pero que nos llevaría mucho más lejos. No nos interesa, tampoco, la actitud paródica, pues ello es lo estilístico individual, el accidente literario, y buscamos lo linguístico permanente. Usaremos los mismos datos en la primera parte de nuestro plantea- 
miento, para ver cómo es posible, al darles una organización distinta a la que les da Alarcos, tomarlos como base para un estudio que permita aplicar a una obra (a cualquier obra) el principio de clasificación en neologismos y esquemas de formación léxica. Mientras que él los organiza así:

\section{Parodias de una palabra dada}

1) Neologismos por condensación: quintainfamia.

2) Neologismos por comparación condensada: libropesía, marivinos, ejemplos ya citados por Durán, a quien no parece conocer Alarcos.

3) Neologismos por adaptación al tema: hidearbitristas.

4) Neologismos por juego de palabras: caraluisa, pretenmuela.

5) Neologismos por diferenciación expresiva: jurisjueces, pelijudas.

\section{REMEDO DE ESQUeMas}

protocornudo, protocuerno, archigato, contraculto, disparatorio, dinerismo, dinerano, diablazgo, diabledad, diablencia, tigresía, marideria, putidoncella, cultipicaño, latiniparla, hembrilatinas, bodar, condar, letradear, abernardar, embodarse, desgalalonar, desengongorar.

A nosotros, en cambio, nos interesaría un orden diferente; un orden en el cual hemos de prescindir, de acuerdo con lo dicho, del aspecto de parodia, de remedo, para quedarnos sólo con el mecanismo gramatical (lexicológico) que ha permitido la formación de esa estructura llamativa, de ese rasgo de estilo. No es necesario restringirse a ello: se puede ver después cómo nuestro autor va aplicando esos procedimientos lexicológicos ya no para remate gracioso o decorado llamativo, sino para los cimientos, vigas, tabiques y cubiertas de su arquitectura literaria. Con ello no nos restringimos a la obra brillante o al escrito paródico, sino que buscamos una caracterización más modesta, menos visible; pero imprescindible para la existencia misma del edificio. Este análisis se asemeja, no al remate espectacular del delantero que Alarcos retrata, sino a la sorda labor del centro del campo, apenas apreciada por el espectador ordinario; pero que es fundamental para llegar al gol. Estamos, alargando nuestro símil, a la busca de ese jugador cuya presencia pasa inadvertida; pero cuya ausencia notan hasta los espectadores menos duchos. He aquí los resultados de esa redistribución:

\section{NeOLogismos}

1) Creaciones literarias: todos los ejemplos de arriba (I-1 al 5).

2) Préstamos. 
II. Esouemas de fORmación léxica

1) Derivación

a) Prefijación $\left\{\begin{array}{l}\text { adjetivos: contraculto } \\ \text { sustantivos: protocuerno, archigato. }\end{array}\right.$

b) Sufijación adjetivos: dinerano, tabacano sustantivos: dinerismo, diablazgo, diabledad, diablen. cia, tigresía verbos: bodar, letradear.

c) Prefijación ( adjetivos: embodado, protocornudo + sufijación sustantivos: desengongoramiento, desengongorismo verbos: desgalalonar.

2) Composición

a) Sustantivo < sustantivo + sustantivo: putidoncella

b) Adjetivo < adjetivo + adjetivo: cultipicaña, calvicasada

c) Adjetivo < adjetivo + verbo: latiniparla

d) Adjetivo < sustantivo + adjetivo: hembrilatina.

El esquema podría ampliarse por la formación de verbos por composición y la parasíntesis; pero, como Alarcos no da ejemplos de estos tipos, no entraremos, por ahora, en ellos. Indicaremos, en cambio, que se puede sacar también fruto del análisis de los cambios de categoría gramatical, y algo veremos de este aspecto.

Lo que haremos ya será plantearnos el estudio concreto en el Libro de Job. Para ello hemos procedido a ir leyendo el libro, separando, a medida que lo hacíamos, las siguientes categorías:

\section{Cultismos}

Latinismos, formas hebreas, helenismos, y similares

Sustantivos compuestos y derivados

Adjetivos compuestos y derivados

Verbos, donde conviene advertir la amplitud del grupo, pues cualquier elemento léxico, mediante -AR, considerado aquí como sufijo, puede hacerse verbo.

Otras construcciones de algún interés.

Nuestro análisis lo es de tipos, no de usos; es una cala, no un recuento exhaustivo; aunque hemos intentado ser completos, no hemos recogido datos numéricos totales de los usos -absolutos o relativos a un tipo. Nos interesa saber qué rendimiento puede dar una aproxima- 
ción como la que intentamos, antes de lanzarnos a empresas mayores (aunque sólo fuere cuantitativamente).

Al seguir el esquema prefijado, se desprenden, casi automáticamente, algunas diferencias entre este Quevedo serio y el Quevedo festivo del que se ocupó Alarcos García. Es posible que estas diferencias sean constitutivas de dos estilos y reflejen dos intenciones distintas del autor; sin embargo, sólo con los datos que manejamos no nos atreveríamos a afirmarlo ni a negarlo.

\section{NEOLOGISMOS}

\section{1) Creaciones literarias}

No hemos encontrado ni un solo ejemplo de ninguno de los tipos del esquema de Alarcos: ni del tipo I, parodias de una palabra dada, ni del II, remedo de esquemas. Podemos decir que falta, por tanto, la intención paródica, y que no se incurre en ella ni una sola vez, o sea, que no hay concesiones en este sentido.

\section{2) Préstamos}

Este apartado puede subdividirse para obtener mejores resultados. Los críticos han señalado cómo Quevedo utiliza pocos préstamos, en toda su obra, y algo de ello hemos adelantado antes. Aunque se trate de una apreciación especulativa, sin comprobar con los correspondientes recuentos, la verdad es que es una consideración que se impone a cualquier lector.

Tratando de ampliar este panorama, hemos decidido subdividir aquí en tres grupos léxicos: los préstamos de lenguas modernas, los cultismos, y los latinismos, grecismos, hebraísmos, etc. Mantenemos siempre las grafías del texto.

\section{a) Préstamos de lenguas modernas}

En este grupo era necesario restringirse a formas que no estuviesen ya asimiladas en la lengua, para lo cual nos hemos fijado, convencionalmente, la barrera del siglo xvi. Se reducen de este modo los préstamos medievales y del primer humanismo. 
Con la restricción antedicha, sólo encontramos dos, en este grupo, ambos italianismos:

brabata, que Corominas y Pascual (DECH) documentan desde 1548-51. gaceta, documentado por Corominas (DCEC) desde el Viage del Parnaso cervantino, de 1614.

\section{b) Cultismos}

Este es el apartado más peligroso de toda la clasificación. No sólo por las dificultades intrínsecas del propio concepto de cultismo, que ahora no vienen a cuento y han sido ya bien señaladas (por J. J. de Bustos Tovar y Roger Wright, entre otros), sino porque, al hacer un grupo distinto con los latinismos más crudos, grecismos y demás, hay formas léxicas que se superponen en dos clasificaciones. Por ello no es ya conveniencia, sino necesidad, lo que nos obliga a insistir en el carácter provisional y de intento de esta clasificación.

Con todas estas limitaciones, hemos reducido las palabras que se incluyen en este apartado a diecisiete (17), cuyas grafías, como de costumbre, mantenemos, aunque ordenándolas con criterios alfabéticos modernos:

aforismo, antiquisima, claúsula, conjeturar, discipulo, fratricida, gentilidad, hypocrita, holocausto, insipiente, jubilar, litigar, particula, repugnante, tabernáculo, Tirano, tropelia.

Hemos excluido, por tanto -y en ello esperamos que no haya discrepancias - las formas como florecer, porque no nos parece que su rasgo característico (conservación del grupo FL- inicial) sea definitivo. Se nos puede objetar, y lo admitimos, la inclusión de gentilidad, cuando gentil está documentado desde las Glosas Silenses (como 'pagano'), y ya aparece en el Cid, mientras que no se incluye iniquidad, a pesar de que inicuo no se documenta con anterioridad a 1499 (Hernán Núñez), siempre según Corominas ( $D C E C$, s.v.v. gente e igual, respectivamente). Vaya uno por otro, o súmense. Litigar y conjeturar están documentados en los diccionarios del $\mathrm{xv}$, antiquisima es un superlativo, que se podría considerar a caballo entre cultismo e italianismo: Cervantes, en el episodio de la Condesa Trifaldi, todavía ironiza con don quijotissimo, escuderissimo, etc., si bien es cierto que él ya emplea este superlativo espontáneamente. Quevedo, como veremos, mantenía también vivos otros procedimientos de formación del superlativo. Otros casos, los menos, sin duda, son innegables: insipiente se usa para traducir el insipiens de una cita latina, mientras que el grecismo avulgarado tropelia se documenta 
por primera vez en 1604, en La Pícara Justina (Corominas, DCEC). Holocausto lo emplea Luis de la Puente $(+1625)$ y Lope, éste en rima con casto (DCEC, s.v. HOLO-). Frente a éstos, voces como repugnante podrían haberse excluido, igual que hicimos con florecer. Las abona, únicamente, el ser relativamente tardía la grafía -gn-, frente a la normal, y previa, - $n$-. La exclusión de otras formas, como indubitable, se debe a que lo más importante en ellas es su formación: IN — BLE, y no se encuentra la palabra dubita, que habríamos incluido en este apartado, o en el siguiente, de los latinismos más crudos. La coherencia que hemos buscado no nos autoriza, por supuesto, a creer que éste sea el único método, o el mejor.

c) Latinismos crudos, grecismos, hebraísmos, etc.

Este apartado comunica con el anterior, y tal vez en doble sentido, pues tropelía pudiera incluirse aquí y phenix o sylogismo allá. Insistimos en que no hacemos cuestión. Hemos atendido a dejar en este grupo las frases escritas por Quevedo en latín (no las citas de otros autores, abundantísimas), los nombres propios y adjetivos derivados de ellos, y las voces que nos parecían, con lo que ello tiene de subjetivo, más crudas (desde el punto de vista de la «cocción» del idioma, o sea, 'menos hechas').

1) Expresiones latinas de Quevedo: se reducen a tres construcciones determinativas, lugares comunes, vas electionis, cor mundi, o relativas a una cita, homo contentionis.

2) Nombres propios y adjetivos derivados: Satanás y Génesis están bien y tradicionalmente introducidos en español. Syra es una forma latinizante para el adjetivo actual siria, mientras que Arabissa se corresponde con el latín arabissa de la cita que traduce. Hypobolimeo, aplicado a Orígenes, y Halicarnaseo, aplicado a Dionysio, no parecen haber triunfado en español. El Paraphrastes, y el hebraísmo Thargum o los Thargumes (comentaristas), también parecen justificarse bien. Más discutibles, por reclasificables, serían anathema, que traduce el mismo término, scisma, hyperboles (masculino), periphrasi, phenix, o sylogismo.

\section{Conclusión parcial}

En lo que concierne a los neologismos, Quevedo se nos muestra moderado. Admite los que podríamos llamar términos técnicos (sylogismo, periphrasi, hyperboles, Thargum), y recoge una serie de formas más o menos nuevas (tropelia, bravata), ya utilizadas antes. Este punto muestra 
con claridad no ser criterio de modernización al que nuestro autor se aficionase. Ausente por completo la intención paródica, falta también totalmente la aplicación que de estos recursos se hace en otras obras.

\section{ESQUEMAS DE FORMACION LEXICA}

\section{1) Derivación}

Para la recta intelección de este apartado hemos de advertir que actuamos como si todos los verbos, por el hecho de serlo, tuvieran un "sufijo" (vocal temática $+R$ ), de modo que no podrán aparecer en el apartado $a$ (prefijación), sino en $b$ (sufijación) y en $c$ (prefijación + sufijación). También hay que considerar que, en este punto, resulta inconveniente diferenciar lo que es continuación directa de una forma latina de lo que es procedimiento modernizador. Aclaramos: virtuoso, poderoso, indubitable, colegir, contextura, proceder, como formas léxicas, son continuación de palabras latinas, de las que derivan directamente; no son, en propiedad, formaciones castellanas son sufijos y prefijos. Esto sería muy importante, y habría de ser diferenciado cuidadosamente, si tratáramos de ver las palabras nuevas que forma Quevedo por medio de los procedimientos de derivación; pero no es así. Lo que nos interesa es que tiene vigencia la formación de adjetivos con -oso, -able, de verbos con el prefijo co-, o pro-, y de sustantivos con el sufijo -ura. Tiene su interés recoger, o tratar de resumir, las formas en -ado, o en re-, a-, per-, o sobre-; pero primero tenemos que saber si esos procedimientos de ampliar el léxico tenían vigencia, en qué modalidad y con qué tipos. Por ello, cuando detrás de cada tipo pongamos algunas realizaciones, no debe entenderse que recogemos todo lo que hay en el texto, sino sólo que damos una muestra: así, el que tras -ABLE vayan indubitable o detestable no quiere decir que no haya más derivados de ese sufijo; es que nuestra preocupación ha sido recoger el tipo en -ABLE, no todos los casos en que aparece. (Esto, naturalmente, no significa que, casualmente, para algunos tipos, no citemos todos los ejemplos del texto.)

a) Prefijación
Adjetivos
DES- deshonesta
DIS- dispuesto
IN- inmunda
PRE- presupuesta. 
Sustantivos

BIS- viznieto, (re)visabuelo

DES- desconsuelo, desdicha, desengaño, desvelo, desverguença

IN- impio ( $e l$, como sustantivo)

PRE- prerogativa (sic)

RE- repregunta, requiebro, resuello, revisabuelo.

b) Sufijación

Adjetivos

-ABLE formidable

-AL infernal, pyramidal

-ARIO contrario, - a

-IMO acerrimo

-IZO resvaladiza

-OR sufridores

-OSO hermoso, poderoso, virtuoso

-UDO linajudo

Sustantivos

\begin{tabular}{|c|c|}
\hline$-\mathbf{A J E}$ & linage \\
\hline -ARIO & temerario (el) \\
\hline -ASCA & borrasca \\
\hline$-\mathrm{CION}$ & $\begin{array}{l}\text { aclamación, comparación, condición, consolación, emulación, lo- } \\
\text { cución, mención, obligación, sujeción }\end{array}$ \\
\hline -DAD & $\begin{array}{l}\text { calamidad, caridad, contrariedad, fecundidad, humildad, pro- } \\
\text { piedad }\end{array}$ \\
\hline- ENCIA & eloquencia \\
\hline -ENDA & fazienda \\
\hline -ERO & estercolero, novelero \\
\hline- IA & soberbia \\
\hline$-1 A$ & villania \\
\hline- ICIA & avaricia \\
\hline -MIENTO & entendimiento \\
\hline -SION & posesión \\
\hline -URA & hermosura \\
\hline \multicolumn{2}{|l|}{ Verbos } \\
\hline$-\mathbf{A R}$ & $\begin{array}{l}\text { calumniar, congojar, engañar, executoriar, honestar(se), ocasio- } \\
\text { nar, reverenciar, sazonar }\end{array}$ \\
\hline -EAR & periphrasear, rastrear \\
\hline -ECER & florecer \\
\hline -IFICAR & calificar, justificar, santificar, testificar \\
\hline -IZAR & autorizar, canonizar, hebraizar. \\
\hline
\end{tabular}


c) Prefijación + sufijación

Ordenamos por prefijos, en primer lugar, para dar luego la lista alfabética de sufijos con los prefijos que les acompañan.

\section{Adjetivos}

Prefijos

DES-, DE- desconocido, desconsolada, desmayada (+ DO)

detestable ( + ABLE)

IN indubitable, innegable (+ ABLE)

Sufijos

-ABLE (combina con DE- e IN-)

-DO (combina con DES-)

\section{Sustantivos}

Prefijos

CON- contextura (+ URA)

CONTRA- contradicción (+ CION)

DES- despeñadero (+ ERO)

desventura (+ URA)

DIS- discordia (+ IA)

EN- enfermedad (+ DAD)

$$
\text { embidia (+ IA) }
$$

EX- exaltación, exortación (+ CION)

IN- iniquidad, inmortalidad (+ DAD)

ingratitud (+ ITUD)

indecencia (+ NCIA)

inocente (el) (+ NTE)

INTER- interpretación $(+\mathrm{CION})$

PER- persecucion (+ CION)

PRE- preservación ( + CION)

PRO- proposición (+ CION)

RE- recognición (+ CION)

reprehension (+ SION)

TRANS- transfiguración (+ CION)

Sufijos

-CION (combina con CONTRA-, EX-, INTER-, PER-, PRE-, PRO-, RE-, TRANS-.)

-DAD (combina con EN-, IN-.)

-ERO (combina con DES-)

-IA (combina con DIS-, EN-)

-ITUD (combina con IN-) 
-NCIA (combina con IN-)

-NTE (combina con IN-)

-SION (combina con RE-)

-URA (combina con CON- y DES-,.)

Verbos

Prefijos (Aunque haya casos de doble prefijo etimológico, como desembarazar y desaprender, hemos preferido no complicar la clasificación, teniendo en cuenta que lo fundamental de la formación, en el texto, es el matiz del primer prefijo. Incluimos también las raices prefijas, como EQUI-. En cuanto a los sufijos con los que se combinan, puesto que no son muy importantes, ni numerosos, sólo atenderemos a si forman verbos en -AR, -ER o -IR.)

A-, AD- abrazar, aconsejar, acordar, administrar, afianzar, afirmar, alegar, amparar, aniquilar, apartar, arrinconar, as(s)egurar, atormentar, avergonzar(se) (-AR) acontecer (-ER)

adquirir, advertir, apercibir, asistir (-IR)

AB- absolver (-ER)

ANTI- anticipar (-AR)

$\mathrm{CO}(\mathrm{N}$ - comparar, computar(se), concordar, confederar(se), congeturar, convidar (-AR)

CONTRA- contrahacer (-ER)

DE(S- degollar, depositar(se), derribar, desalentar, desamparar, desatar, descarar(se), descifrar, desembarazar, despeñar, desperdiciar, despoblar, despreciar, desquitar, desterrar, desvariar, desvelar(se) (-AR)

desaprender, desconocer, deshacer (-ER)

describir, descubrir, desmentir, destruir (-IR)

DIS- disimular (-AR)

disponer (-ER)

discurrir, distribuir (-IR)

EN- encaminar, encarcelar, encumbrar, enjoyar (-AR)

enmudecer (-ER)

ENTRE- entretejer (-ER)

EQUI. equiparar (-AR)

EX- exaltar, execrar, expurgar (-AR)

extender (-ER)

excluir (-IR)

IN- imputar (-AR)

incurrir, inquirir (-IR)

INTRO- introducir (-IR)

PER- perficionar, perseverar (-AR)

perecer (-ER)

percibir, permitir, perseguir (-IR)

PRE- predominar, preservar (-AR)

preceder (-ER)

prevenir (-IR) 
PRO- $\quad$ profanar, provocar (-AR)

$$
\begin{aligned}
& \text { proceder (-ER) } \\
& \text { proseguir (-IR) }
\end{aligned}
$$

RE- rebujar (traduce inuoluens), reconciliar, rematar, remediar, renunciar (-AR)

reconocer, reprehender, resplandecer (-ER)

remitir, resistir, restituir (-IR)

SOBRE- sobrevenir (-IR)

TRA(N)S- trasladar (-AR)

Distribución por conjugaciones

-AR: A-/AD-; ANTI-; CON-; DE(S-; DIS; EN-; EQUI-; EX-; IN-; PER-; PRE-; PRO-; RE-; TRAS-

-ER: A-; AB-; CO(N-; CONTRA-; DE(S-; DIS-; EN-; ENTRE-; EX-; PER-; PRE-; PRO-; RE-.

-IR: A-/AD-; CO(N-; DES-; DIS-; EX-; IN-; INTRO-; PER-; PRE-; PRO-; RE-; SOBRE-

\section{2) Composición}

\section{Adjetivos}

bien afortunado (es un superlativo, con bien en el lugar que hoy ocupa muy, de modo que no es un compuesto propiamente dicho);

bienaventurado; mal intencionado; mal sonante (los dos últimos, separados gráficamente, son, en realidad, una unidad léxica).

\section{Sustantivos}

(el) por què (siempre separado, una vez en cursiva, pág. 270, y otra en redonda, pág. 272).

tapaboca.

\section{Verbos}

bendecir (podría tomarse como raíz prefija, como hicimos con equiparar, o traer esta forma a este apartado); multiplicar (casi podría hacerse la misma observación, salvo que plicar carece de existencia independiente).

\section{3) OTRAS COSTRUCCIONES DE ALGỨN INTERÉS}

Hemos observado, dentro de los tipos estudiados, al menos cuatro casos de sustantivación, en sentido propio, es decir, de paso a la categoría morfológica (paradigmática) de sustantivo: se trata de (el) temerario, (el) impio, (el) inocente y (el) por qué. Se podrían añadir otros, como p. ej. un lascivo (p. 237 a). 
También conviene señalar aquí cómo el autor es consciente de los valores de los prefijos, tanto en su oposición a la forma cero (dicha) desdicha), como en su alternancia formal (perseguir/proseguir; preceder/proceder).

También incluiremos aquí, aunque éste no es ahora nuestro objetivo, dos observaciones sintácticas. La primera es de carácter general, y se refiere a la abundancia con la que el autor emplea la construcción predicativa, con ser (patente o latente) o con otros verbos: no son raros párrafos como éste (241 a):

Las desdichas, las prisiones, pèrdida de hazienda, de la casa, y de los hijos, llamase desgracia, y es antidoto al veneno del cariño con que se tienen.

La segunda es más bien una curiosidad, y se limita a registrar la presencia en el texto de un infinitivo dependiente de un sustantivo al que se une por el nexo a: era deuda à pagar en Christo (pág. 279 b).

\section{Análisis de los datos}

A tenor de lo que hemos ido diciendo, podemos señalar ahora algunos puntos que resuman lo que - según nos parece- se desprende del análisis. Antes de ello conviene repetir que las páginas precedentes son una cala, sin pretensión de exhaustividad, y que si parecen más com. pletas en algún punto (prefijos antepuestos a verbos, p. ej., eso obedece a la superior riqueza del material, que ha ido obligando a una taxonomía más detallada. Lo que sí esperamos es que, al completar esos datos, no se puedan alterar sustancialmente los resultados que ahora vamos a exponer; sin que ello nos obligue, por otro lado, a ser excesivamente parcos aquí.

Vamos a ir resumiendo los datos en cuadros esquemáticos, para mayor comodidad (las cifras sólo pueden ser indicativas):

\section{NEOLOGISMOS}

$\begin{array}{lcc}\text { creaciones } & \text { préstamos (de } & \text { cultismos } \\ \text { literarias } & \text { lenguas modernas) } & \text { (restringido) }\end{array}$

$\mathbf{0}$
grecismos, latinismos crudos, hebraismos, etcétera

17 
II. ESQUEMAS DE FORMACION LEXICA

(para la modernización)

\begin{tabular}{|c|c|c|c|c|c|c|}
\hline & & & Adjetivos & Sustantivos & Verbos & Total \\
\hline & \multicolumn{2}{|c|}{ Prefijación } & 4 & 5 & - & 9 \\
\hline \multirow{4}{*}{$\begin{array}{l}\text { DERIVACIÓN } \\
\text { (tipos) }\end{array}$} & \multicolumn{2}{|c|}{ Sufijación } & 9 & 14 & 5 & 28 \\
\hline & prefijac. & Pr. & 2 & 13 & 19 & 34 \\
\hline & + & & & & -AR & \\
\hline & sufij. & Su. & 2 & 9 & $\begin{array}{l}3 \text {-ER } \\
\text {-IR }\end{array}$ & 14 \\
\hline $\begin{array}{l}\text { CoMPOSICIÓN } \\
\text { (tipos) }\end{array}$ & & & 1 & 2 & 1 & 4 \\
\hline & & & 18 & 43 & 28 & 89 \\
\hline
\end{tabular}

Para comprender el cuadro no hay que olvidar que los totales absolutos por clases morfológicas no son significativos, al ser distinto el criterio de clasificación del verbo, para el cual no se han contado los prefijos separadamente, y se han reducido a las tres vocales temáticas los tipos de sufijación combinada con la prefijación. En los adjetivos, en cambio, los prefijos y sufijos se han contado dos veces, pues se repiten, de modo que, en total, sólo son cuatro tipos de prefijos y nueve de sufijos.

En el sustantivo, por su parte, la situación es más compleja, pues hay tres sufijos que aparecen sólo combinados con prefijos (-TUD; -NCIA; -NTE), ocho sufijos que hemos recogido sólo en formas sin prefijos (-AJE); -ARIO; -ASCA; -NCIA; -ENDA; -IA; -ICIA; -MIENTO), y seis comunes (-CION; -DAD; -ERO; -IA; -SION; -URA).

En lo que respecta a los sustantivos con prefijos, dos de éstos se dan en formas sin sufijo (BIS-; EN-), cuatro son comunes (DES-; IN-; PRE-; RE-), y los ocho restantes sólo aparecen en formas con sufijos (CON-; CONTRA-; DIS-; EX-; INTER-; PER-; PRO-; TRANS-), lo que hace un total de catorce (14).

Podemos ahora reconstruir el cuadro, atendiendo a los prefijos y sufijos distintos, tan sólo de este modo:

$\begin{array}{lcccc} & \text { Adjetivos } & \text { Sustantivos } & \text { Verbos } & \text { Total } \\ \text { Prefijos } & 4 & 14 & 19 & 37 \\ \text { Sufijos } & 9 & 17 & 7 & 33 \\ \text { Total } & 13 & 31 & 26 & 70\end{array}$


El cuadro es todavía incompleto, pues, para los verbos, al atender a prefijación y sufijación conjuntamente, no hemos diferenciado más subgrupos que las tres conjugaciones, como ya hemos advertido. Aunque podríamos corregirlo, reelaborando el material, con ello obtendríamos una complicación del mismo muy superior, sin proporción con su rendimiento, de manera que preferimos no hacerlo, dado el carácter de cala de este ensayo, en el que tanto insistimos.

El paso siguiente será ver, conjuntamente, los prefijos y sufijos utilizados para todas las categorías, que resumimos en la tabla siguiente:

\section{PREFIJOS}

\section{Adjetivos sustantivos Verbos categorias}

A-, AD-

AB-

$x$

1

ANTI-

$\begin{array}{ll}x & 1\end{array}$

ANT

$x$

$x$

1

BIS-

$\mathrm{CO}(\mathrm{N}-$

CONTRA-

$x$

1

DE(S-

DIS-

$x$

EN-

$x$

ENTRE-

EQUI-

EX-

IN-

$x$

INTER-

INTRO-

$x$

PER.

PRE-

$\times$

PRO-

RE-

SOBRE-

TRA(N)S-

21

4

$x$

$x$

$x$
$\times$

$\times$

$x$

$x$

$x$

14

2

2

3

3

2

1

1

2

3

1

1

2

3

2

$x$

2

$x$

1

2

$\times \quad 2$

19 


\section{SUFIJOS}

Adjetivos Sustantivos Verbos Total

\begin{tabular}{|c|c|c|c|c|}
\hline -ABLE & $x$ & & & 1 \\
\hline -AJE & & $x$ & & 1 \\
\hline$-A L$ & $x$ & & & 1 \\
\hline -AR & & & $x$ & 1 \\
\hline -ARIO & $x$ & $x$ & & 2 \\
\hline$-A S C A$ & & $x$ & & 1 \\
\hline$-\mathrm{CION}$ & & $x$ & & 1 \\
\hline -DAD & & $x$ & & 1 \\
\hline -DO & $x$ & & & 1 \\
\hline -EAR & & & $x$ & 1 \\
\hline -ECER & & & $x$ & 1 \\
\hline -ENCIA & & $x$ & & 1 \\
\hline -ENDA & & $x$ & & 1 \\
\hline -ER & & & $x$ & 1 \\
\hline -ERO & & $x$ & & 1 \\
\hline -IA & & $x$ & & 1 \\
\hline$-1 A$ & & $x$ & & 1 \\
\hline -ICIA & & $x$ & & 1 \\
\hline -IFICAR & & & $x$ & 1 \\
\hline -IMO & $x$ & & & 1 \\
\hline$-I R$ & & & $x$ & 1 \\
\hline -ITUD & & $x$ & & 1 \\
\hline -IZAR & & & $x$ & 1 \\
\hline- IZO & $x$ & & & 1 \\
\hline -MIENTO & & $x$ & & 1 \\
\hline -NCIA & & $x$ & & 1 \\
\hline -NTE & & $x$ & & 1 \\
\hline$-\mathrm{OR}$ & $x$ & & & 1 \\
\hline $.0 S O$ & $x$ & & & 1 \\
\hline -SION & & $x$ & & 1 \\
\hline -UDO & $x$ & & & 1 \\
\hline -URA & & $x$ & & 1 \\
\hline 32 & 9 & 17 & 7 & - \\
\hline
\end{tabular}

$\operatorname{LXV}, 10^{\circ}-2 .^{\circ}-4$ 
Los dos cuadros últimos, bien analizados, nos permiten darnos cuenta de que, a pesar de ser el número de prefijos diferentes (21) menor que el de sufijos (32), el rendimiento de los primeros es muy superior, ya que los segundos suelen ser privativos de una categoría, mientras que en los prefijos dominan los comunes a dos o tres categorías a los limitados a una.

\section{CONCLUSIONES}

Con todas las limitaciones varias veces repetidas, y que no nos cansaremos de recordar, podemos obtener algunos resultados sobre la configuración de la lengua de Quevedo en el Libro de Job.

1) Nuestro autor utiliza los recursos que le brinda la lengua, e incluso con ciertas limitaciones:

a) Prefiere la derivación a la composición.

b) Reduce el campo del préstamo innovador, y, atendiendo al carácter culto de su obra, es llamativo constatar el reducido número de tecnicismos crudos (targumes y similares), y la casi total ausencia de frases propias en latín (es decir, fuera de los textos ajenos que cita, y traduce). A ello podría añadirse el cuidado con el que traduce sus citas latinas, a lo que no fue ajena la instancia de don Bartolomé Santos de Risoba, obispo de León.

c) No introduce términos formados sobre esquemas de la lengua, con fin de innovación, del tipo de los que resumimos antes, según Alarcos, tan utilizados en otras obras.

d) Dentro de la derivación, el recurso a la prefijación le permite una gran sutilidad, y riqueza de posibilidades, al poder combinar un prefijo con distintas categorías morfológicas derivadas de la misma raíz (p. ej., perseguido, persecución, perseguir), e incluso ampliar este juego léxico a alternancias de prefijos (perseguir, proseguir) o a formas con y sin prefijo (desdicha/dicha). Así, v.gr., véase el juego de PRO-/PER-en 249 b: «Todo lo que pudo proseguir à Job, le persiguiò».

Por todo ello, podemos caracterizar su actuación lingüística como de fijación (y esplendor) de medios que le ofrece ya la lengua, y que están patentes cuando comparamos el crecimiento del léxico entre dos diccionarios; (véase, especialmente, por convenir a la época, la realizada entre el Tesoro de Covarrubias y el Diccionario de Autoridades, por I. Acero: 1978, inédito, resumen en F. Marcos Marín: 1979, 124-128). Quevedo sería, consecuentemente con ello, un modernizador de la len- 
gua, no un reformador, de acuerdo con la distinción que establecimos antes: utiliza con vigor y riqueza esquemas que su instrumento idiomático ya posee.

2) Además, esa sabia utilización no es indiferente a los fines del autor, su situación, y el contenido del libro. Y en ello los prefijos, junto a la selección del léxico, tienen algo que decir: si analizamos los empleos de sus distintas formas, veremos que hay tres de ellos (de(s-, dis$e$ in-), comunes a adjetivos, sustantivos y verbos, caracterizados por el rasgo común de negación o supresión. A ellos podemos sumar en-, exy contra-, comunes a sustantivos y verbos, $a b-\mathrm{y}$ anti- (junto a algunos usos de $a$-), específicos del verbo. Todo ello, con una frecuencia notable, y sobre un contenido general de la obra que está plenamente situado dentro de la visión ascética y moralizadora.

El Quevedo del Libro de Job, que arroja sobre la vida y sobre su propia existencia una dolorida mirada, al comprobar qué poco le ha quedado de la pasada edad, transmite ese pesimismo a la selección de procedimientos linguísticos de su texto, mostrándonos cómo su báculo idiomático, tal vez ahora más corvo, no era, sin embargo, menos fuerte. El recuerdo de la muerte, sin embargo, impregna, una a una, las páginas de esta lamentación, en la que está buscando otra esperanza.

\section{Francisco Marcos MarfN}

Universidad Autónoma de Madrid

\section{REFERENCIAS}

ACERo DURANTEZ, Isabel, 1978. «Tesoro Lexicografico de Sebastian de Covarrubias y «Diccionario de Autoridades», Memoria de Licenciatura (inédita), Universidad de Valladolid.

Aguirre Asurmendi, Máximo, 1959. La oración subordinada en Quevedo, Tesis de la Universidad de Murcia. (Cfr. NRFH, XVIII, 1965-66, pág. 347, núm. 18.4000, y Crisby, 6.)

Alarcos Garcta, Emilio, 1955. «Quevedo y la parodia idiomática», $A O, \mathrm{~V}, 3-38$, y en Homenaje al Profesor Alarcos García, I, Valladolid, 1965, 443-472.

Alemany, José, 1925. aAcerca del origen de una M*, Bol. R.A.E., XII, 674-683.

ALonso, Dámaso, 1950. «Dos calas en el estilo de Quevedo», en Poesía española: Ensayo de métodos y límites estilisticos, Madrid, Gredos, VI, 661-669.

Bonilla y San MarTIN, Adolfo, 1904. «Sobre las construcciones del relativo 'quien' en la Historia de la vida del Buscón, de Quevedox, en Anales de literatura española (años 1900-1904), Madrid, 180-186. 
Bustos Tovar, Jesús, 1974. Contribución al estudio del cultismo léxico medieval, Madrid, R.A.E.

Castro, Américo, 1926. «El 'gato' y el 'ladrón' en el léxico de Quevedo», Archivio Glottologico Italiano (Turín, n.s., I, 140-142.

CrocchinI, H. E., 1965. «Quevedo y la construcción de imágenes emblemáticas», R.F.E., XLVIII, 393-405.

CrosBy, James O., 1976. Guia bibliográfica para el estudio crítico de Quevedo, Londres, Grant \& Cutler (res. de R. M. Price, en BHS, LV, 1978, 160-161.

DURAN, Manuel, 1954. «Rasgos 'modernos' del estilo de Quevedo», Hispania, XXXVII, 429-431.

—, 1955. «Algunos neologismos en Quevedo», Modern Language Notes (Baltimore), LXX, 1955, 117-119.

ETtinghuUsen, Henry, 1972. Francisco de Quevedo and the Neostoic Movement, Oxford University Press.

Garcla Moreno, A., 1976. «Juan de Pineda y el Libro de Job», Estudios Bíblicos, XXXV, 23-47, 165-185.

HeRbert, Karl, 1922. Zur Syntax des Quevedo, tesis de la Universidad de Francfort del Meno (109 págs. mecanografiadas) (Crosby, 499).

Ladrón de Cegama, Emilio, 1954. El tratado «Providencia de Dios», de Francisco de Quevedo. Pensamiento y estilo, tesis doctoral de la Universidad de Barcelona (NRFH, XVIII, 1965-66, 347, núm. 18-4009; Crosby, 554).

LAZARO CARRETER, Fernando, 1974. Estilo barroco y personalidad creadora, Madrid, Cátedra.

LeRner, Lía Schwartz, 1971. Creaciones estilísticas en la prosa satírica de Quevedo, tesis de la Universidad de Illinois, Urbana (DA, XXXII, 1971, 973 A; Crosby, 584).

- 1973. «El juego de palabras en la prosa satírica de Quevedo», Anuario de Letras (México), XI, 1973, 149-175.

LIDA, Raimundo, 1972. «Pablos de Segovia y su agudeza: Notas sobre la lengua del Buscón», Homenaje a Casalduero: crítica y poesía, ed. Rizel Pincus Sigele y Gonzalo Sobejano. Madrid, 285-298.

- 1972 b. «Sobre el arte verbal del Buscón», Philological Quarterly (Iowa City), LI, 1 (Hispanic Studies in Honor of Edmund de Chasca), 255-269.

LOPEZ GRIGERA, Luisa, 1965. El estilo de Quevedo en sus tratados ascéticos, tesis de la Universidad de Madrid (Cfr. Rev. Univ. Madrid, XIV, 1965, 218-219.)

-, 1969, ed. La cuna y la sepultura, Madrid, R.A.E.

MARcos MARTiN, Francisco, 1979. Reforma y modernización del español, Madrid, Cátedra.

1980. Curso de gramática española, Madrid, Cincel-Kapelusz.

Piero, Raúl A. del, 1957. «Dos citas latinas de Quevedo», RF, LXIX, 67-71.

—, 1958. "Observaciones para una edición crítica del Job de Quevedo», Filologia Romanza, V, 343-364.

-, 1598 b. «Algunas fuentes de Quevedo», NRFH, XII, 36-52.

-, 1958 c. «Quevedo y Jacques Salian de Aviñón», BHi, LX, 367-374.

- 1958 d. Quevedo y la Polyanthea», Hispanofila, 4, 49-55.

-, 1959. «Two notes on Quevedo's Job», The Romanic Review, L, 9-24.

-, 1969. eLas fuentes del Job de Quevedo», BFUCh, XX, 17-133.

QUBVEDo, Francisco de, 1852. Obras, tomo primero, ed. de Aureliano FernándezGuerra y Orbe. Madrid, Rivadeneyra, BAAEE. 
- 1724. Obras Posthumas y Vida de Don Francisco de Quevedo y Villegas, Madrid (Imprenta de Juan de Ariztia, a costa de Francisco Laso).

Sarmiento Gonzalez, Ramón, 1977. «Inventario de elementos gramaticales de los siglos XVIII y XIX», Bol. R.A.E., LVII, 129-142.

- 1978. «La gramática de la Academia: historia de una metodología», $R S E L, 8$, $105-115$.

- 1979. «Filosofía de la Gramática de la Real Academia Española», Anuario de Letras, XVII, 59-96.

- 1980. «La doctrina gramatical de la R.A.E. (1771) en la línea de las gramáticas filológicas del Renacimiento», Anuario de Letras, XVIII (en prensa).

Soons, Alan, 1970. "Los entremeses de Quevedo: Ingeniosidad linguiística y fuerza cómica», Filologia e Letteratura (Nápoles), XVI, 424-456.

VAzouez DE CASTRO, Isabel, 1958. Estilistica y sintaxis en "La hora de todos», tesis de la Universidad de Madrid (NRFH, XVIII, 1965-66, 670, núm. 18-7900; Crosby, 977).

WRIGHT, Roger, 1976. «Semicultismo», Archivum Linguisticum, VII, 13-28.

YNDURAIN, Francisco, 1955. «Refranes y 'frases hechas' en la estimativa literaria del siglo XVII», $A F A$, VII, 103-130. 